\title{
A psicanálise no caleidoscópio da história: interpretações e perspectivas da história da psicanálise no Brasil
}

\section{Psychoanalysis in the kaleidoscope of history: interpretations and perspectives of the history of psychoanalysis in Brazil}

\author{
Pedro Felipe Neves de Muñoz \\ Professor, Departamento de História/Pontifícia Universidade Católica do Rio de Janeiro. \\ pedrodemunoz@hotmail.com
}

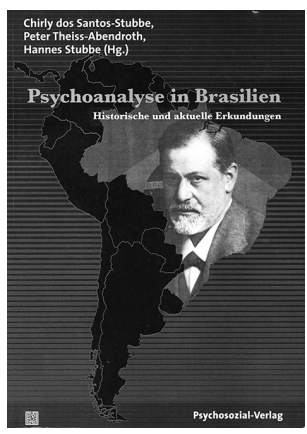

SANTOS-STUBBE, Chirly dos; THEISS-ABENDROTH, Peter; STUBBE, Hannes (Ed.). Psychoanalyse in Brasilien: historische und aktuelle Erkundungen. Gießen: PsychosozialVerlag. 2015. 193p.
Ta teoria da história, aproximamos a história e o caleidoscópio 1 (Reis, 2006). A psicanálise também nos leva a ele e às diversas formas de ver e auscultar o passado. Nessa operação, Freud adentrou no terreno da linguagem e fez surgir um novo arcabouço conceitual, constantemente reformulado por ele e por seus seguidores. Lacan realizou o "retorno a Freud" para constituir a psicanálise como saber (Assoun, 1991).

Chirly dos Santos-Stubbe (Universidade de Ciências Aplicadas, em Mannheim), Peter Theiss-Abendroth (psiquiatra e psicanalista em Berlim) e Hannes Stubbe (Universidade de Colônia), no entanto, se voltaram para outros capítulos dessa história, segundo eles, menos conhecidos entre os alemães: a história da psicanálise no Brasil. Os três organizaram o livro Psychoanalyse in Brasilien: historische und aktuelle Erkundungen, publicado pela editora Psychosozial-Verlag.

O livro é resultado do projeto "Sigmund Freud nos trópicos", que investiga o desenvolvimento da psicanálise no mundo de língua portuguesa. Nele, há diferentes colaborações de especialistas brasileiros e alemães que problematizam a clínica de hoje e apresentam diversas interpretações sobre a recepção da psicanálise no Brasil, por intermédio de distintos atores históricos estrangeiros e brasileiros do Sudeste e do Sul do país, bem como do surgimento de sociedades psicanalíticas em solo brasileiro.

Os organizadores abrem o livro desconstruindo clichês sobre o Brasil. Mostram a importância internacional atual do país e citam o desconhecimento entre os alemães sobre a sociedade brasileira, a história e o fazer psicanalítico em terras latinas, exceto pelo caso argentino e, talvez, pelo chileno. Lembram que os colaboradores estrangeiros do livro dominam o português e conhecem a cultura brasileira. 
No segundo texto do livro, Hannes Stubbe faz uma exegese da tese de Genserico Aragão de Souza Pinto (1888-1958), defendida em 1914, sob a orientação de Antonio Austregésilo (1876-1960). Ela foi a primeira tese sobre Freud escrita em português. Nela, Freud foi recebido sob o crivo dos referenciais psiquiátricos franceses, em meio ao debate sobre a degeneração, hereditariedade e perversão. Houve um complexo processo de importação e tradução de Viena via Paris para o Rio/São Paulo, mas não sem resistências. A cultura católica serviu muitas vezes como elemento mediador da sexualidade freudiana, ainda que se deva considerar a coexistência da poligamia e formas de amor livre, inclusive no catolicismo popular. No texto de Pinto, a psicanálise é um instrumento para o progresso e para dar ordem ao labirinto dos transtornos psíquicos. Seria um método terapêutico e de reeducação afetiva a serviço dos médicos.

No terceiro capítulo, Hans Füchtner problematiza a recepção da psicanálise no Brasil, anterior à "febre lacaniana" dos anos 1970. Ele analisa a trajetória de intelectuais brasileiros interessados na psicanálise que dominam o alemão e que foram capazes de superar as barreiras linguísticas: Juliano Moreira (1873-1933), Julio Porto-Carrero (1887-1937), Franco da Rocha (1864-1933), Durval Marcondes (1899-1981), Arthur Ramos (1903-1949) etc. Alguns deles chegaram a trocar cartas com Freud. Além disso, o autor discorre sobre os psicanalistas alemães que vieram ao Brasil para formar os psicanalistas brasileiros (Lehranalytiker), no contexto das primeiras sociedades psicanalíticas: Adelheid Koch (1896-1980), Hans Thorner (1905-1991), Werner Kemper (1899-1975) e Anna Kattrin Kemper (1905-1979). Encerra o texto analisando o tema da tradução.

No quarto capítulo, Cristiana Facchinetti e Rafael Castro analisam o papel de Juliano Moreira na recepção da psicanálise, principalmente, nos anos 1920. Ela fez parte da agenda de reformas de Moreira, na qual a psiquiatria kraepeliana ganhou preponderância. Além de realizar palestras sobre Freud, Moreira integrou a Sociedade Brasileira de Psicanálise, criada em 1927, na cidade de São Paulo. No ano seguinte, surgiu a Seção Rio da referida sociedade, da qual Moreira tornou-se presidente. Ele atuou ainda na Liga Brasileira de Higiene Mental, onde um serviço de psicanálise foi organizado, em 1926, servindo como um instrumento de diagnóstico da nação, da educação científica, terapia dos anormais e controle dos instintos. Ao divulgar as teorias de Freud, Moreira se apropriou da psicanálise como ciência auxiliar e uma ferramenta da psiquiatria.

Marina Massini, por sua vez, busca elucidar o processo de introdução da psicanálise no Brasil como um fenômeno singular. Ela faz uma genealogia da cultura indígena, jesuítica, médica e terapêutica anteriores ao século XIX, em que o uso da palavra teve centralidade, abrindo um terreno fértil para a psiquiatria, psicologia moderna e psicanálise do século XX. Massini retoma a distinção entre pioneiros e precursores, abraça a tese do sincretismo na cultura brasileira e do ecletismo no uso da psicanálise, em meio a um processo de criativa assimilação. Dedica particular atenção à psicanálise em Marcondes, Arthur Ramos e Oswald de Andrade. Encerra seu texto analisando o processo de institucionalização da psicanálise, com a criação das sociedades psicanalíticas ligadas à International Psychoanalytic Association (IPA).

No sexto capítulo, Peter Theiss-Abendroth fala sobre as particularidades da psicanálise na sociedade brasileira: questões econômico-sociais em geral e do acesso à análise, permanências da cultura patriarcal, além de suas experiências com analisandos brasileiros na Alemanha. 
Já André Martins realizou um estudo sobre conceitos de Freud, Lacan e Winnicott para mostrar que as ideias deste último se adaptaram singularmente ao contexto cultural brasileiro. Apresenta os conceitos de desejo e instinto em Winnicott, bem como sua rejeição ao conceito freudiano de pulsão de morte. Por fim, argumenta que a sociedade brasileira não segue o modelo da neurose da sociedade vitoriana.

No último texto, o psicanalista, produtor de cinema e doutorando em psicologia (Paris VII) Francisco Capoulade faz generalizações sobre a dificuldade de combinar a psicanálise e o povo brasileiro, que gozaria de uma sexualidade livre e de habilidade para o riso. Seria um povo da falta de uniformidade e da miscigenação, no sentido de Gilberto Freyre. Para explicar isso, ele produziu o filme Hestórias da psicanálise: leitores de Freud (2016), com a participação dos autores dessa coletânea. Nele, busca-se mostrar como a psicanálise foi recebida, interpretada e praticada aqui.

Em suma, o livro é uma excelente leitura sobre o lugar da medicina e da psiquiatria nacional na recepção conservadora da psicanálise, na primeira metade do século XX. Contudo, o leitor sentirá falta de um capítulo dedicado exclusivamente ao período da ditadura militar brasileira. Nota-se que dois textos, apesar de escritos em estilo e forma mais próximos da teoria psicanalítica do que da história, contribuem ao apresentar os problemas do texto freudiano, as alternativas oferecidas por outros psicanalistas, as principais questões da clínica da atualidade, a forma como vivemos e sofremos hoje no Brasil. Por fim, são questionáveis as continuidades entre o uso da palavra na cultura indígena, jesuítica e terapêutica (séculos XVI-XIX) e a recepção da técnica psicanalítica no século XX. Embora seja muitas vezes bem explorada a relação entre as matrizes culturais brasileiras (europeia, indígena, asiática e africana) e os dilemas da inserção da clínica psicanalítica, algumas generalizações sobre o ser do brasileiro podem incomodar o leitor.

\section{REFERÊNCIAS}

ASSOUN, Paul-Laurent.

O freudismo. Rio de Janeiro: Jorge Zahar. 1991.

HESTÓRIAS...

Hestórias da psicanálise: leitores de Freud. Direção:

Francisco Capoulade. Brasil: Cabelo Duro

Produções. 96 min. 2016.
REIS, José Carlos.

História e teoria: historicismo, modernidade, temporalidade e verdade. Rio de Janeiro: Editora FGV. 2006.

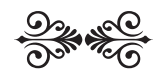

